\title{
Morpho-Orthographic Processing in Children with Autism Spectrum Disorder: The Case of Hebrew Orthography
}

\author{
Sara Ferman ${ }^{\mathrm{a}, \mathrm{b}} \quad$ Amalia Bar-On ${ }^{\mathrm{a}}$ \\ ${ }^{a}$ Department of Communication Disorders, School of Health Sciences, Sackler Faculty of Medicine, \\ Tel Aviv University, Tel Aviv, Israel; ${ }^{b}$ The Center for Academic Studies, Or Yehuda, Israel
}

\section{Keywords}

Autism spectrum disorder - Reading ·

Graphemic-phonemic decoding · Morpho-orthographic

identification · Pseudowords

\begin{abstract}
Objective: Most studies on word reading in children with autism spectrum disorder (ASD) focus on graphemic-phonemic decoding and the direct orthographic route. To extend the scope, we investigated morpho-orthographic identification beyond graphemic-phonemic abilities. Patients and Methods: The original study included 31 sixth-grade children with ASD and comparison groups of typically developing (TD) children: 23 age-matched children, 15 third-graders, and 17 second-graders. The groups were compared regarding reading of morphologically based Hebrew pointed pseudowords to examine graphemic-phonemic decoding, and unpointed pseudowords to test morpho-orthographic identification. To better focus on morpho-orthographic identification processes, we eventually included only children with a minimum threshold of $\geq 65 \%$ correct in reading pointed pseudowords, thereby excluding 11 children with ASD, 1 TD age-matched child, and 1 TD third-grader. Results: About
\end{abstract}

half of the children with ASD eventually included were as accurate as the TD second-graders in reading unpointed pseudowords, and slow in reading both pointed and unpointed pseudowords. The other half were as accurate as their typical peers in reading unpointed pseudowords, but slightly slower. Conclusion: The results highlight the difficulties many Hebrew-reading children with ASD experience in using morpho-orthographic processes beyond their difficulties in using graphemic-phonemic processes, demonstrating effortful (slow) reading. While this study can be considered a pilot investigation, further studies are needed.

(c) 2017 S. Karger AG, Basel

\section{Introduction}

Autism spectrum disorder (ASD) is a neurodevelopmental condition characterized by deficits in social communication; restricted, repetitive patterns of behavior, in-

This work was conducted at The Center for Academic Studies, Or Yehuda, and at the Department of Communication Disorders, School of Health Sciences, Sackler Faculty of Medicine, Tel Aviv University, Tel Aviv, Israel.

\section{KARGER}

(c) 2017 S. Karger AG, Basel

E-Mail karger@karger.com

www.karger.com/fpl
Sara Ferman, $\mathrm{PhD}$ 43 Gutman Zvi St. Rishon LeZion 75465 (Israel)

E-Mail saraf@post.tau.ac.il 
terests, or activities; and the fact that the presentation of the symptoms is not better explained by intellectual disability alone [1]. It is a spectrum disorder ranging from very mild to severe impairments. ASD may affect many aspects of thinking, learning, and behavior, and many children with ASD display unique patterns of development, both as a group and as individuals [2]. Although some areas of intellectual development such as fluid reasoning and visual spatial processing are relatively strong [3], other areas such as knowledge and particularly daily living skills are significantly delayed [4]. Individuals with ASD may demonstrate repetitious behavior, focus on details, and have difficulty integrating information, extracting meaning, and distinguishing relevant details [5]. There is a large group of children with ASD who have poor language skills, and some of them manifest a language profile similar to that of children with developmental language delay (or specific language impairment) $[6,7]$.

These cognitive and language deficits can exert a tremendous influence on reading skills in this population [8]. Although not all children with ASD learn to read [5], there is evidence indicating an early and spontaneous onset of word decoding ability in some children with ASD [9-11], and good reading accuracy skills in both children [9, 12-16] and adults [17] with ASD. In some studies, reading accuracy was higher than the given participants' IQ $[18,19]$.

The most commonly reported reading profile for children with high-functioning ASD is one of intact or even precocious word decoding (exceptional reading skill levels) combined with reduced reading comprehension [5, $12,14,20-24]$. This profile of reading behavior has been called hyperlexia, which is the opposite of that of dyslexic individuals, who often demonstrate stronger comprehension despite weaker decoding $[14,25]$.

The often unexpected findings of precocious word reading ability in children with ASD are not yet fully understood. There is some evidence that rather than using graphemic-phonemic decoding, children with ASD may rely mostly on direct visual access pathways, using rote memorization of visual pattern recognition, namely, the orthographic lexicon [5,26]. Some researchers have suggested that orthographic processing is stronger than phonological processing in these children. For example, Sparks [10, 27] studied 3 hyperlexic children over an 8 -year period and concluded that their phonemic awareness was low as compared to their word reading level. Therefore, their main reading pathway could be the direct orthographic route, as opposed to graphemic-phonemic

Morpho-Orthographic Processing in Children with ASD decoding in typically developing (TD) readers $[11,24,28$, 29]. Conversely, the finding that hyperlexic children with ASD were weaker than nonhyperlexic children with ASD at visual processing tasks [22] does not lend support to the view that holistic visual rote learning of word forms can explain the precocious word reading ability in this population.

Alternative explanations relate the precocious word reading to exceptionally good graphemic-phonemic decoding skills. Many researchers have noted that hyperlexic children manifest a strong interest in reading to the exclusion of everything else; this might result in extensive reading experience and practice, thereby contributing to exceptional word decoding abilities [30]. Cardoso-Martins and Da Silva [13] suggested that hyperlexics' indifference to language as a meaningful, communicative device may be the key to the exceptionally good and precocious development of their ability to compute letter-sound relations implicitly, on the basis of statistical learning. Nation [31] proposed that cognitive strengths in ASD, including a preoccupation with circumscribed interests and a close attention to details, can account for their exceptionally good word decoding processing.

Graphemic-phonemic decoding is typically measured by the pseudoword reading task, which is widely considered to be one of the most critical predictors of successful reading acquisition $[25,32]$. Since reading nonwords aloud cannot rely on the orthographic lexicon, readers are obliged to connect novel letter strings to sequences of phonemes. If children with ASD read by relying heavily on graphemic-phonemic decoding, nonword reading should be intact.

Findings of nonword reading ability in individuals with ASD vary extensively. Some studies found that children [13, 20,26 and adolescents [15] with ASD did not differ from TD controls in nonword reading tasks. Minshew et al. [15], for example, found that high-functioning adolescents with autism performed similarly to their age-matched counterparts in both word identification (sight word vocabulary reading) and word attack (decoding of nonwords). Moreover, their nonword reading was slightly better than their sight word identification, suggesting a heightened ability to apply phonetic analytic skills to decode nonwords. This finding is in line with that of O'Connor and Klein [16], who showed that children with ASD read phonetically regular words more easily than phonetically irregular words, indicating an intact phonetic decoding strategy.

However, it is notable that many studies that found high nonword reading abilities in children with ASD only included children who were reading at a reasonably ad- 
vanced level [15, 20]. Nation et al. [5] stated that "caution is required when generalizing from homogeneous, highfunctioning readers with ASD, especially given the wide variation in cognitive and linguistic skills seen in individuals with ASD" (p. 911).

Studies that included large heterogeneous populations of children with ASD clearly showed that not all such children exhibit exceptional nonword reading ability [5]. Many recent studies have found considerable variability across the ASD samples, with performance ranging from floor to ceiling levels $[5,12,33]$ and subgroups displaying severe difficulties. For example, in the group of 41 participants in the study by Nation et al. [5], of the sample of 32 children who were able to read words at all, $42 \%$ were at least 1 SD below population norms for nonword reading, and $22 \%$ scored at least 2 SD below population norms. In the study by White et al. [33], approximately half of the ASD sample exhibited word decoding difficulties similar to those of a group of readers with dyslexia. A high rate of word reading impairment was also found by Åsberg et al. [34] in their study sample of high-functioning girls with ASD. Difficulties were also manifested in a lettersound spelling task, where the performance of hyperlexic children with ASD was lower than that of typical readers [13], but superior to that of nonhyperlexic children with ASD [22]. Nation et al. [5] concluded that the low levels of decoding skills in many children with ASD constitute one of the factors in reading comprehension deficits in ASD. This notion is supported by studies that demonstrated relatively poor performance in phonological awareness tasks by children with ASD [13,26], although hyperlexic ASD children demonstrated better phonological processing skills than nonhyperlexic ASD children [22].

Understanding the graphemic-phonemic correspondence is essential for learning to read. However, writing systems do not merely reflect phonological sequences; rather, they encode various aspects of the language system, including its morphology [35]. Thus, above and beyond phonology, which has preoccupied research on reading for many years [36], readers should also be able to identify morphological units in written words.

\section{The Role of Morphology in Learning to Read}

As decoding skills develop and children gain more experience with written words, they become capable of using larger units, such as syllables, morphemes, or whole words, to access meaning faster [37-39]. The repeated encounter with morphologically complex words that share the same stem (e.g., price in priceless and pricey) or the same affix (e.g., less in nameless and speechless) highlights the consistencies between morphological form and meaning. This supports the establishment of orthographic patterns that represent morphemic units in young readers [40]. Equipped with these representations, children can identify complex words fast and accurately. Carlisle and Fleming [41] found, for example, that second- and thirdgrade English-speakers read derived words (e.g., hilly) faster and more correctly than they read matching monomorphemic words (e.g., silly).

Converging evidence suggests that as early as elementary school age, children make use of morphological information when they read morphologically complex words. This has been demonstrated in various languages including Italian [42], French [43], Arabic [44], and Hebrew $[45,46]$. This view gained support from many studies showing a positive correlation between morphological awareness and reading development $[47,48]$ as well as reading disabilities [49]. Further support for using morphological knowledge in reading is emerging from studies demonstrating the contribution of morphological intervention to improved reading skills [50].

Languages differ in the extent to which they encode linguistic information within the word [51]. The role of morphology in word recognition is enhanced in languages with a rich word-internal structure $[52,53]$. Hebrew is a Semitic language with a rich morphology that is widely reflected in its orthography $[54,55]$.

\section{Hebrew Orthography}

Hebrew is encoded in two orthographic versions: one is phonologically transparent, and the second is phonologically opaque but morphologically transparent [56]. The phonologically transparent version, namely, pointed script, is mainly used for beginning reading instruction, but also in poetry and most religious texts. It provides the reader with full phonological information by means of three graphemic components [45]: 18 letters denoting consonants, a set of 4 AHWY (אהוי) letters denoting both consonants and vowels, and a set of diacritical marks, called nikud, which mainly denote vowels and also stop/ spirant alternation (e.g., $\mathrm{k} / \mathrm{x}$ ).

The second version, namely, unpointed script, is the default version for native speakers who are proficient readers. This script relies on letters alone to designate both consonants and vowels, with no nikud diacritics. Consonantal representation of unpointed words is exhaustive, except for stop/spirant alternations in 3 letters. In contrast, vowels are represented inconsistently and incompletely by the dual-function AHWY (אהוי) letters DOI: $10.1159 / 000479062$
Ferman/Bar-On 
alone. The 5 Hebrew vowels, $a, e, i, o$, and $u$, are almost always represented at the word-final position, where both the letters A ( () and $\mathrm{H}(\boldsymbol{\pi})$ denote both the vowels $a$ and $e$, and the letter W ( ) designates both the vowels $o$ and $u$. In contrast to the full (yet ambiguous) representation of word-final vowels, internal $a$ and $e$ are almost never represented, and $i$ representation is governed by complex conditions. As a result of the extreme underrepresentation of vowels, almost none of the unpointed words can be read by simply using phonological decoding. Recovering the vowels in reading unpointed words - at least words the reader encounters for the first time - requires the use of morphological cues provided by the root-and-pattern morpho-orthographic structure of the Hebrew words.

The bulk of Hebrew content vocabulary (nouns, verbs, and adjectives) is made up of two nonconcatenated interwoven morphemes: root and pattern. The spoken root, the core lexical meaning of the word, is an unpronounceable discontinuous morpheme and is inserted into patterns that specify a prosodic-vowel template. It often consists of additional peripheral consonantal or consonantvowel affixes. For example, the words šèkef (slide), šakuf (transparent), and miškèfet (binoculars) are made up of the same root $s$ - $k$ - $f$ and the patterns $C \dot{e} C e C, C a C u C$, and miCCèCet, respectively.

The structure of the unpointed written words reflects the nonconcatenative, interwoven, bimorphemic nature of the spoken word [55]: root radicals are fully represented in the written word, while patterns, being composed mostly of vowels, have lesser orthographic representation. Cues for pattern identification in reading are the peripheral 6 function letters standing for pattern prefixes or suffixes, as well as 2 vowel letters, Y (') and W ( $)$ ), denoting the internal vowels $i, o$, and $u$ [45]. For example, the written forms of the three examples above are ŠQP (שקף), ŠQWP (שקוף), and MŠQPT (משקפת), respectively. Pattern is not represented at all in the first word; it is represented by only the internal vowel letter $\mathrm{W}(\mathrm{l})$ in the second, and by the peripheral letters $M(\Omega)$ and T (ת) in the third. Note that none of the word vowels is represented in the first and third words, and only one vowel $(\mathrm{u})$ is represented in the second word. Despite its spare representation, pattern cues constitute the main device that assists in the recovery of the vowels of the unpointed word. Thus, in learning to read Hebrew, children have to acquire the morphoorthographic mapping strategy.

\section{Learning to Read Hebrew}

Share and Bar-On [56] propose a triplex model of learning to read Hebrew that consists of three developmental phases. The first phase is related mainly to the first grade, when children learn to read pointed script. With a phonological decoding relying heavily on diacritics, Hebrewspeaking children achieve a high level of accuracy (about $80 \%$ ) in reading the (relatively) easily decipherable pointed script at the end of the first grade [57]. Second-graders, still using diacritics, become more and more skilled in decoding pointed words. As their experience with written words increases, they rely less on low-level sublexical phonology and gradually move on to the next, second phase of faster and more fluent reading, based on developing lexico-morpho-orthographic identification strategies.

Relying on morphology is critical in reading Hebrew, particularly in the first years of learning to read, when readers encounter many unpointed words for the first time. Filling in the missing vowel information is viable only by using morphological information. The ability to apply the morpho-orthographic identification strategy is typically measured by reading morphologically based Hebrew pseudowords $[45,58]$. Shany et al. [58] showed that second-graders read pointed morphologically based pseudowords significantly more accurately ( $76 \%$ success) than they read non-morphologically based pseudowords (60\% success). Bar-On and Ravid [45] tested seven groups of novice and skilled readers in reading unpointed morphologically based pseudowords - a condition that necessitated the use of morphological information. A significant increase in reading accuracy (from 30 to 57\%) occurred between the beginning and the end of the second grade, with a gradual development in reading accuracy between the end of the second grade and the third and fourth grades.

The acquisition of lexico-morpho-orthographic identification skills permits the transition (which occurs mostly in the fourth grade) to the third phase, namely, reading unpointed script. Interestingly, children who are at the stage of transitioning from pointed to unpointed texts are less accurate than younger readers in reading pointed pseudowords. This phenomenon is explained by a tendency to ignore the phonological bottom-up information in favor of using higher-level strategies of morpho-orthographic identification [58].

Due to their ambiguous nature, orthographic and morpho-orthographic identification are essential but not sufficient for successful reading of unpointed text. About a quarter of the words of every unpointed text are heterophonic-homographic, i.e., a letter string that can be read in two or more ways. For example, the above example MŠQPT (משקפת) - represents not only miškèfet (binocular) but also mešakèfet (she reflects). The high level of lexical ambiguity of unpointed Hebrew text requires heavy 
reliance on the sentential context [59]. However, the role of context in reading Hebrew is beyond the scope of the current study, which aims to explore the use of phonological and morphological information in single-word reading.

\section{The Present Study}

Findings regarding word reading abilities in individuals with ASD vary extensively, ranging between atypically superior $[18,19]$, typical $[5,12,14,15,26]$, and very delayed $[5,12]$ word reading skills. It is still unclear what underlies the various reading abilities in ASD children. Recent evidence indicates that word identification requires a complex multidimensional coding, including not only graphemic-phonemic (phonological mediation) and direct orthographic (rote holistic visual learning of word forms) processes, but also morpho-orthographic identification processing $[60,61]$. Interestingly, despite the considerable evidence supporting the notion of the critical role morphology plays in reading, most studies that tested reading in children with ASD focused on graphemic-phonemic decoding and the direct orthographic route. As far as we know, no research has hitherto attempted to provide any fine-grained empirical evidence concerning the use of morphological processing in reading among children with ASD.

The goal of the current study was to expand the scope by investigating not only graphemic-phonemic processing but also morpho-orthographic identification - a process that resides between the phonological sublexical level and the whole-word level in children with ASD. The main question was whether Hebrew-speaking children with ASD demonstrate typical or atypical profiles of reading as regards the ability to use morpho-orthographic above and beyond graphemic-phonemic processes in word reading. The existence of two versions of Hebrew orthography (the transparent pointed script and the opaque unpointed script) afforded a useful framework for addressing our goal. We compared accuracy and speed of reading two types of morphologically based pseudowords: (1) pointed pseudowords, the reading of which can rely on both phonological information, provided by diacritics, and morphological information, reflected in morpho-orthographic patterns, and (2) unpointed pseudowords, where vowel recovery in reading relies mostly on morpho-orthographic information. Using pseudowords rather than real words afforded a neutralization of the lexico-orthographic processes from the morphological and phonological processes and an evaluation of the involvement of the two latter processes in reading single words. Finally, in order to try to cope with the issue of a delay versus deviation in reading among children with ASD, we compared children with ASD to typical peers as well as to TD younger readers.

Given that accuracy and speed are sensitive and accepted measures for reading abilities, our specific questions were as follows: (1) Do children with ASD exhibit a typical profile of accuracy in reading pointed and unpointed pseudowords? (2) Do they exhibit a typical profile of speed in reading pointed and unpointed pseudowords? (3) Do they exhibit a typical profile of correlations between accuracy and speed in reading both types of pseudowords? Our hypotheses posited that children with ASD will experience difficulties in reading pointed pseudowords, that is, in using graphemic-phonemic decoding, and since graphemic-phonemic decoding precedes morpho-orthographic knowledge, they will experience even more difficulties in reading unpointed pseudowords. The difficulties will be manifested in both accuracy and speed.

\section{Method}

\section{Participants}

Eighty-six Hebrew-speaking children with Hebrew-speaking parents were recruited for this study: (a) 31 children with ASD aged 10 years 3 months (10:03 years) to 13:03 years $($ mean $=12: 01)$ and (b) three groups of TD children, (1) 23 age-matched children aged 11:02-12:03 years $($ mean $=11: 06),(2) 15$ third-graders aged 8:01-9:00 years (mean $=8: 07)$, and $(3) 17$ second-graders aged 7: 00-7:10 years $($ mean $=7: 04)$. Here we also compared $11-$ to 12-year-old children with ASD to early TD readers (second- and third-graders), since, at this age, Hebrew readers are proficient in phonological decoding and are progressing to the second stage of using morphological strategies [45]. This could be a useful approach when coping with the question of a delay or deviation in the reading abilities of children with ASD.

All participants came from middle-class families and were enrolled in public schools in the center of Israel. Of the 31 children with ASD, 12 were recruited from a special education elementary school specializing in the education of children with ASD, and 19 were recruited from special classes for children with ASD in regular schools. Before starting school, all children with ASD were assessed by psychiatric specialists and were diagnosed according to the Diagnostic and Statistical Manual of Mental Disorders (DSM-IV) [1] criteria for autistic disorder, and according to the WISC (Wechsler Intelligence Scales for Children)-V. According to their test results, they were assigned to a special school for children with ASD (IQ $>70$ ) or to special classes in regular schools (IQ $>85$ ). We recruited only children with ASD who, based on their teachers' reports, had learned to read and were relatively fluent readers of short pointed paragraphs. The teachers of the children with ASD at the special school reported that the children were able to talk and communicate verbally, but were below age level with respect to all aspects of the language. Nevertheless, many of them were slow and inaccurate readers whose errors occurred particularly when they read vowels. 
According to their teachers' reports, their reading reflected that of second- and third-graders, despite the fact that they were in the sixth grade. According to the teacher's report, all children who attended the special classes in the regular schools were able to talk, communicate, and read. Ten of them were integrated into a regular fifth-grade class for at least one course, 5 were very good students, 2 had reading comprehension difficulties, and 1 was language impaired. The TD children were recruited from regular classes in regular schools. According to their teachers, they behaved typically for their ages, and did not have any reported special educational needs, history of ASD, or language or reading delay.

Our main goal was to evaluate morpho-orthographic identification processing in reading of children with ASD. Considering that the ability of graphemic-phonemic decoding is the sine qua non to the development of the ability of morpho-orthographic identification, we tried to avoid investigating children with difficulties in graphemic-phonemic decoding. Therefore, we decided to include in this study only children who reached a minimum threshold of $\geq 65 \%$ correct in reading pointed pseudowords. This minimum threshold was calculated as 1.75 SD (19.4\%) below the mean of percent correct of all typical readers (84.4\%) in reading pointed pseudowords. After applying this criterion, 11 children with ASD ( 5 from the special school and 6 from the special classes) who demonstrated $25-60 \%$ correct $($ mean $=42)$ in reading pointed pseudowords, and 2 TD children (1 age-matched child and 1 thirdgrader) who manifested $60 \%$ correct in reading pointed pseudowords, were excluded from the study. Eventually, 73 children were included in this study - 20 with ASD who had a mean of $82.75 \%$ correct $(S D=12.98$, range $=65-100)$ and 53 TD children who had a mean of $85.75 \%$ correct $(S D=11.07$, range $=65-100)$ in reading pointed pseudowords. A $t$ test revealed that there was no difference between the mean of the children with ASD and the general mean of the three TD groups.

\section{Materials}

In order to evaluate the ability to use phonological and morphological information in reading single words, we employed two lists of morphologically based pseudowords: 20 pointed and 20 unpointed. Both lists were made up of pseudoroots interwoven with real morphological patterns. The pointed list was taken from the Hebrew Standardized Reading and Writing Achievement Test Alef ad Taf [62]. The morphological patterns of the pointed pseudowords reflected both nouns (13) and verbs, and comprised 6 two-syllable words and 14 three-syllable words (2.7 syllables on average). Since the pseudowords were pointed, each one represented a single phonological form. The accurate reading of items that the readers have never seen before relies on the phonological decoding process, whereby the reader linearly decodes and connects a sublexical letter plus diacritic grapheme units. The reading can also be enhanced by morpho-orthographic identification, where the morpho-orthographic cues invoke the appropriate morphological pattern [45].

The unpointed list was taken from Bar-On [63]. Although each of the unpointed pseudowords can be potentially decoded in many phonological forms, only one or two of them are compatible with one or two genuine morphological patterns. An example of this is the pseudoword MBHST (מבחסת). The accurate morphological identification of this word is mivxèset (which corresponds to the noun pattern miCCèCet) or mevaxèset (which corresponds to the verb pattern $m e C a C e ̀ C e t$ ). However, there are at least another 26 possible phonological readings of this word, all of which are nonmorphological, such as mabaxasat, mivxaset, mebxesat, and so on. Thus, the correct morphological identification of unpointed pseudowords mainly reflects the activation of larger units, i.e., morphemic units. Four of the 20 unpointed pseudowords are heterophonic-homographic, i.e., pseudowords that represent two morphological patterns (e.g., MBHST), while the remaining 16 are nonhomographic. Half of the pseudowords represent noun patterns and half of them represent verbs. The number of syllables in a word ranges from two to four: two syllables ( 5 words), three syllables (11 words), and four syllables ( 4 words) (2.95 syllables on average).

\section{Procedure and Measures}

Children were seen individually for one meeting at school, in a quiet room far away from everyday distractions. The meeting lasted approximately $15 \mathrm{~min}$. The pseudowords in each list were presented in a large (16-point) font and were organized in two columns on one page. The reading of the pointed pseudowords was assessed first, followed by the reading of the unpointed pseudowords. Each participant was instructed as follows: "The words on this sheet are words that you have never seen before - invented words. Please read each word aloud from top to bottom. Please note that I will time how long it takes you to read them, but try to read as accurately as possible and at your own pace." Incorrect responses to the reading trials were not corrected, nor did the child receive any feedback with regard to his/her responses. The participants' oral reading was recorded and transcribed. We measured accuracy as well as time in seconds (speed) of reading.

\section{Results}

\section{Graphemic-Phonemic Decoding and}

Morpho-Orthographic Identification Abilities

The group average accuracy (\% correct) and time (s) of reading each list (pointed and unpointed pseudowords) attained by the ASD group were compared to those attained by each of the TD groups, i.e., the age-matched children, third-graders, and second-graders. Where necessary, we conducted post hoc pairwise comparisons at the 0.05 level for simple effects and for interactions. The means and SD of reading accuracy and reading time of both lists in the four groups are shown in Table 1.

Reading Accuracy. A two-way ANOVA that examined the effect of group (four groups) and list (pointed, unpointed) on reading accuracy revealed a significant interaction between group and list $(F(3,69)=11.97, p<0.0001)$ (Fig. 1). There were also found main effects for group $(F(3,69)=7.65, p<0.0001)$ and for list $(F(1,69)=31.92$, $p<0.0001)$. We chose not to elaborate upon the two effects in light of the interaction. We applied the post hoc Ryan-Einot-Gabriel-Welsch multiple-range test in order to analyze the differences between groups for each list. In the accuracy of reading the pointed list, a significant dif- 
Table 1. Reading accuracy and reading time of pointed and unpointed pseudowords in children with ASD and the three TD control groups

\begin{tabular}{|c|c|c|c|c|c|}
\hline \multirow[t]{2}{*}{ Group } & \multirow[t]{2}{*}{$N$} & \multicolumn{2}{|c|}{ Accuracy, \% correct } & \multicolumn{2}{|c|}{ Reading time, s } \\
\hline & & pointed & unpointed & pointed & unpointed \\
\hline ASD & 20 & & & & \\
\hline Mean & & 82.75 & 59.00 & 88.05 & 113.50 \\
\hline Range & & $65-100$ & $25-85$ & $26-181$ & $36-255$ \\
\hline $\mathrm{SD}$ & & 12.29 & 21.25 & 35.50 & 57.09 \\
\hline TD age matched & 22 & & & & \\
\hline Mean & & 87.04 & 85.23 & 50.45 & 53.30 \\
\hline Range & & $70-100$ & $50-100$ & $24-76$ & $23-100$ \\
\hline SD & & 8.68 & 12.48 & 11.88 & 20.40 \\
\hline TD third-graders & 14 & & & & \\
\hline Mean & & 78.57 & 81.79 & 54.43 & 56.93 \\
\hline Range & & $65-100$ & $60-100$ & $36-80$ & $29-78$ \\
\hline SD & & 10.64 & 12.49 & 11.75 & 15.18 \\
\hline TD second-graders & 17 & & & & \\
\hline Mean & & 90.00 & 65.59 & 61.75 & 68.18 \\
\hline Range & & $65-100$ & $60-100$ & $36-80$ & $29-74$ \\
\hline SD & & 11.86 & 14.46 & 19.18 & 20.39 \\
\hline All TD children & 53 & & & & \\
\hline Mean & & 85.755 & 78.02 & 55.13 & 59.03 \\
\hline Range & & $65-100$ & $25-100$ & $24-181$ & $23-255$ \\
\hline SD & & 11.07 & 15.58 & 15.12 & 19.90 \\
\hline
\end{tabular}

ASD, autism spectrum disorder; TD, typically developing.

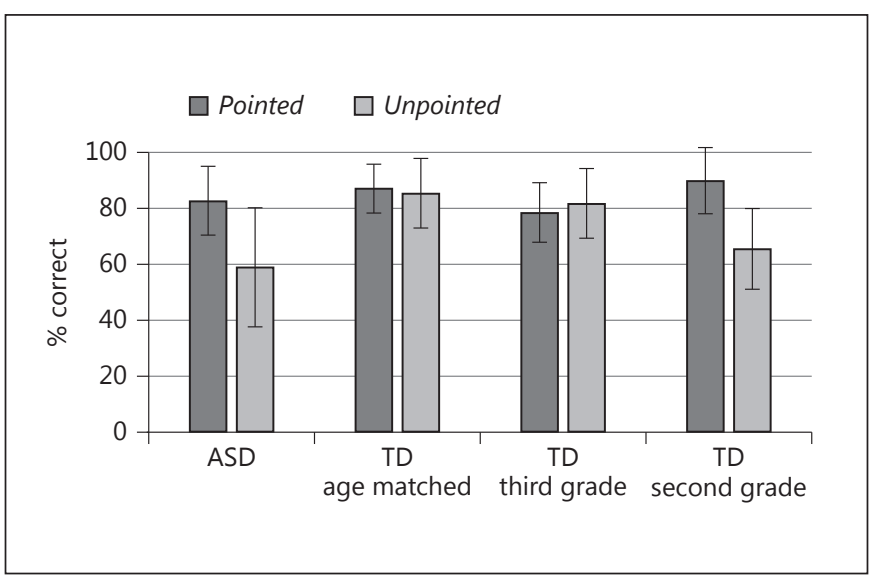

Fig. 1. Comparisons of accuracy performance between the children with ASD and the three control groups (TD age matched, TD in the third grade, and TD in the second grade) in reading pointed versus unpointed pseudowords. Error bars indicate SD of the mean. ASD, autism spectrum disorder; TD, typically developing. ference $(p<0.05)$ was only found between the two younger TD groups, i.e., the second- and third-graders, with the third-graders being less accurate. In the accuracy of reading the unpointed list, the ASD group did not differ significantly from the TD second-grader group, and both groups read significantly less accurate $(p<0.05)$ than the TD third-grader and the TD age-matched groups, who did not differ from each other.

Reading Time (Speed). A two-way ANOVA that examined the effect of group (four groups) and list (pointed, unpointed) on reading time revealed a pattern of findings that was similar to the one revealed for reading accuracy. There was an interaction of group $\times$ list in reading time $(F(3,69)=5.92, p<0.001)$ (Fig. 2$)$ and main effects for both group $(F(3,69)=13.23, p<0.0001)$ and list $(F(1,69)=$ $15.77, p<0.0001)$. Again, we chose not to elaborate upon the two effects in light of the interaction. The post hoc analysis of the differences between groups for each list (Ryan-Einot-Gabriel-Welsch multiple-range test) showed that the children with ASD read significantly more slowly $(p<0.05)$ than the three TD groups for both lists. 


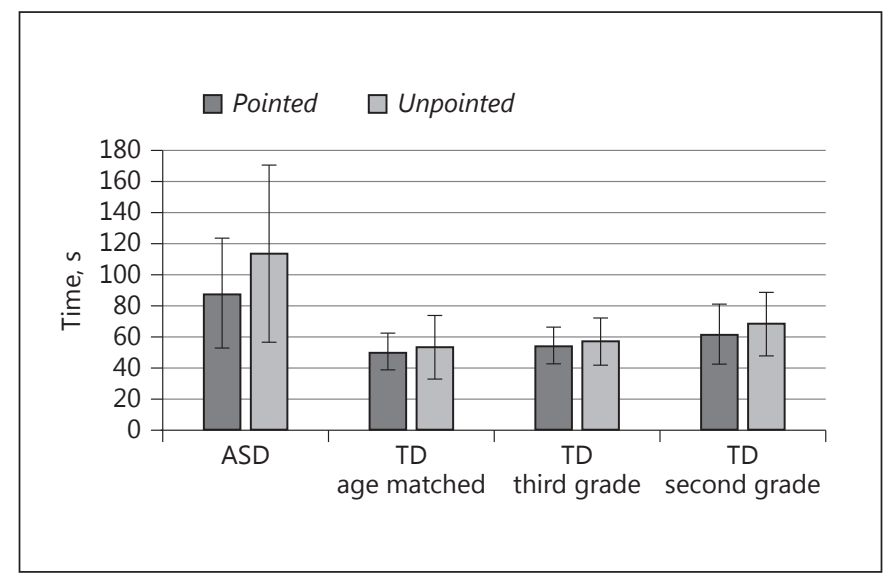

Fig. 2. Comparisons of time performance between the children with ASD and the three control groups (TD age matched, TD in the third grade, and TD in the second grade) in reading pointed versus unpointed pseudowords. Error bars indicate SD of the mean. ASD, autism spectrum disorder; TD, typically developing.

Table 2. Pearson correlations between accuracy (\% correct) and speed (s) in reading the pointed and unpointed pseudoword lists in each of the four groups

\begin{tabular}{lcl}
\hline Group & Pointed & Unpointed \\
\hline ASD & $-0.546^{*}$ & $-0.848^{* * *}$ \\
TD age matched & 0.002 & $-0.583^{* *}$ \\
TD third-graders & -0.127 & -0.111 \\
TD second-graders & -0.360 & -0.360 \\
\hline
\end{tabular}

ASD, autism spectrum disorder; TD, typically developing. ${ }^{*} p<0.05,{ }^{* *} p<0.01,{ }^{* * *} p<0.001$.

Correlation between Accuracy and Speed in Reading the Pointed and Unpointed Lists

To better characterize the graphemic-phonemic decoding and morpho-orthographic identification skills among the children with ASD and the three TD age groups, we also calculated the correlations between accuracy and speed for each list and for each group (Table 2).

A Pearson correlation analysis revealed that among the children with ASD, there was a strong correlation between accuracy and speed for the unpointed list, with some of them demonstrating low accuracy and speed scores and others demonstrating high accuracy and speed scores, as well as a weak correlation between accuracy and

Morpho-Orthographic Processing in Children with ASD

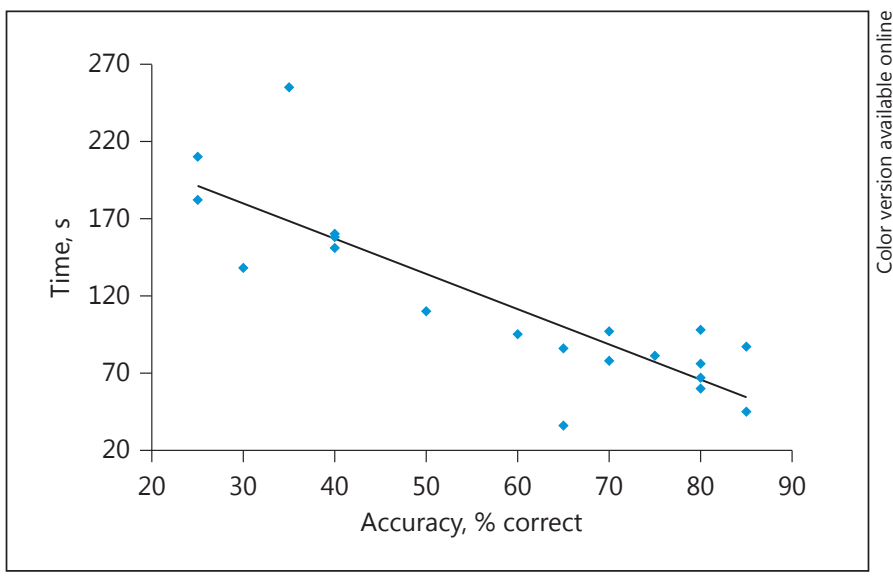

Fig. 3. Scatterplot showing the relationship between accuracy (\% correct) and speed (s) in reading unpointed pseudowords by children with ASD $(n=20)$. The reference line indicates parity between the two measures.

speed for the pointed list. A correlation between accuracy and speed in reading the unpointed list was also found among the TD age-matched group, with most of them demonstrating high accuracy and speed scores. Nevertheless, no correlation between accuracy and speed was found among the two younger TD groups. The significant correlation between accuracy and speed in reading $u n$ pointed pseudowords among children with ASD is presented in Figure 3.

\section{Discussion}

The study sought to characterize the abilities of Hebrew-speaking children with ASD in the intermediate school years to use morpho-orthographic identification strategies for graphemic-phonemic decoding in reading pseudowords. In typical reading development, well-established phonological decoding skills precede morphoorthographic identification. This enables the reader to allocate resources to the larger units, i.e., the morpho-orthographic structures of the written word [37-39, 45, 64]. Therefore, to address our goal, we included only children who demonstrated "good enough" graphemic-phonemic decoding abilities ( $\geq 65 \%$ accuracy in reading pointed pseudowords).

According to this criterion, while only $3 \%$ ( 2 out of 55 ) of the TD children were excluded from our final study, 
$35 \%$ (11 out of 31 ) of the children with ASD were excluded. Moreover, whereas the 2 TD children who were excluded manifested a borderline accuracy score (60\%), the children with ASD who were excluded manifested lower scores (mean $=45 \%, \mathrm{SD}=11.37$, range $=25-60$ ) in reading Hebrew pointed pseudowords. Our rate of poor graphemic-phonemic decoding is somewhat higher than that reported by Nation et al. [5] for their ASD sample when reading English pseudowords (22\% of their ASD sample scored $<2$ SD below population norms) but lower than that reported by White et al. [33] (about half of the ASD sample exhibited word decoding difficulties similar to those of a group of readers with dyslexia).

We expected most of the children with ASD who would be excluded from the study because of poor reading accuracy of pointed pseudowords to come from the special school, demonstrating lower graphemic-phonemic achievements than the children who were recruited from special classes in regular schools. However, the picture was slightly different; the children with ASD who were excluded $(n=11)$ came from both educational settings: $42 \%$ (5 out of 12) from the special school and 30\% (6 out of 19) from the special classes in regular schools. Moreover, the children from these different educational settings had almost identical scores in reading pointed pseudowords (mean $=45, \mathrm{SD}=10.9$, range $=30-60$, and mean $=45.8, \mathrm{SD}=11.7$, range $=25-55$, for the special school and special classes, respectively). This may suggest that not only a large group of children with ASD who attended special autism schools, but also a large group of children with ASD who studied in special classes in regular educational settings, were very poor at using graphemic-phonemic decoding.

The children with ASD from the special school who were excluded displayed lower accuracy scores in reading the pointed pseudowords (45\%) than the TD second-and third-graders (90 and 79\%, respectively). This finding is not in line with the teachers' reports describing them as readers at the level of second- to third-graders. It is possible that the teachers overestimated their students. Furthermore, it is highly probable that the teachers' reports were based on the children's ability to read pointed real words. In the current study, however, we tested ASD children's ability to read pointed pseudowords. Pseudoword reading poses a unique challenge to the reader, since he cannot monitor his reading by means of the orthographic lexicon. Recent studies have reported that there are at least subgroups of individuals with ASD who struggle with reading pseudowords even when their real-word reading is developmentally adequate for their age. This pattern was not observed in the TD children, who exhibited a high correlation between real-word and pseudoword reading levels $[5,13,26]$. Based on these studies, we can speculate that some of the children with ASD could read pointed real words better than pointed pseudowords.

While many (35\%) of the children with ASD displayed poor graphemic-phonemic decoding, the remaining 20 children with ASD displayed good graphemic-phonemic decoding - as accurate as that of the three TD control groups. This finding supports the notion of a large variability in graphemic-phonemic decoding skills among children with ASD $[5,2,33]$.

Of primary importance was the observed finding that children with ASD as a group failed to make the same progress as their typical peers or as typical third-graders, and that they remained at the level of second-graders in their ability to use a morpho-orthographic identification strategy. Both the TD third-graders and the age-matched children displayed a similar accuracy level in reading pointed and unpointed pseudowords, indicating an almost mature ability to use morpho-orthographic identification. Second-graders, however, could read pointed pseudowords accurately, but they were less accurate in reading unpointed pseudowords, indicating that they were still establishing their morpho-orthographic strategy [45].

The present finding of a delay in the ability of children with ASD to use a morpho-orthographic identification strategy for reading unpointed pseudowords could be associated with oral language skills, including morphological and lexical knowledge, as well as with cognitive abilities. Unfortunately, these abilities were not tested in the current study. Nevertheless, several explanations that may be useful for future studies are offered here.

Reading unpointed pseudowords is a challenging task, since most of the information concerning the vowels is missing and the only way to complete it is by identifying the morpho-orthographic patterns embodied in the written word [45]. Studies in various languages have shown that children with typical reading development utilize morphological information in order to read morphologically complex words [42-44, 46]. In other words, learning to recognize and use morpho-orthographic patterns in reading morphologically based unpointed pseudowords may be at least partially dependent on stable and mature morphological knowledge. Therefore, a deficit in morphological knowledge that may occur in children with ASD $[65,66]$ can at least partially explain the delay they experience in using a morpho-orthographic identification strategy. It is noteworthy that 
some studies associated poor language skills among individuals with ASD with poor phonological decoding [5] or poor reading comprehension $[67,68]$. Here, however, we conjecture that poor language skills among individuals with ASD may be associated with limitations in the morpho-orthographic identification strategy involved in reading.

Cognitive deficits can also explain some of the difficulties experienced by children with ASD in morpho-orthographic identification. Cognitive impairments are the intermediary link between the neuroanatomical abnormalities found in individuals with ASD and the behavioral symptoms that characterize them [69]. It is highly likely that learning to identify the morpho-orthographic units of written words and using them for reading are implicit; no one teaches these components of written words, and readers are not aware of using these representations. It has been suggested that children with ASD are impaired in implicit learning [69]. Individuals with ASD have been found to experience difficulty in disengaging and shifting their attention [70], and it has been proposed that this difficulty would prevent them from noticing relationships between different parts of a stimulus [70].

Moreover, reading pointed pseudowords and reading unpointed real words can rely on "stable anchors": the first is dependent on graphemic-phonemic decoding of the diacritics, and the second on meaning and/or orthographic representations. Unpointed pseudowords lack both of these anchors and therefore depend on the ability to switch to another reading process that focuses on morphological identification. Thus, it is a challenge that may require flexible thinking and switching. There is evidence that both of these executive functions may be impaired in individuals with ASD [71, 72].

\section{Reading Speed (Time)}

In this study, we found robust and consistent evidence that, as a group, children with ASD were very slow readers; they were slow in reading the pointed Hebrew pseudowords, and even more so the unpointed ones. They were slower than all three TD groups, which did not differ from one another. They were one and a half times slower than the TD children ( 88 vs. 55 s, children with ASD vs. the average of the three TD groups) in reading the pointed pseudowords, and twice as slow (113 vs. 59 s, children with ASD vs. the average of the three TD groups) in reading the unpointed pseudowords. The reading speed of the 11 children with ASD who were excluded from the study was even poorer (104 and $121 \mathrm{~s}$, pointed and unpointed pseudowords, respectively).

Morpho-Orthographic Processing in Children with ASD
Interestingly, 12-year-old children with ASD were as accurate as - but much slower than - the TD secondgraders in reading the pointed pseudowords. In transparent orthographies like German, Spanish, and pointed Hebrew, the consistency of graphophonemic correspondence could imply that speed rather than accuracy is sensitive to the level of reading proficiency $[73,36]$. Therefore, reading speed is considered to be a strong indicator of reading level, that is, the mastery of the reading skill. The accepted notion is that fast reading constitutes the substrate for fluent reading, and that the latter constitutes the substrate for reading comprehension $[74,75]$.

Furthermore, while the ASD group was significantly slower in reading the unpointed pseudowords than in reading the pointed pseudowords, the reading speed of the three TD groups was not affected by the type of pseudoword (Fig. 2). Given that slow performance may indicate effortful processing [76], our findings suggest that reading the pointed - let alone the unpointed - pseudowords was very effortful for the children with ASD but not for the TD children. These results support the notion that while the children with ASD struggled with graphemic-phonemic decoding, they struggled much more with the implementation of morpho-orthographic strategies.

Effortful reading may lead to an avoidance of reading. Similarly, poor reading comprehension that may occur in individuals with ASD may discourage reading. Therefore, children with ASD may be less motivated to read, resulting in less reading. In addition, there are reports that the curricula of students with ASD focus on life skills rather than on academic and literacy skills [77]. Thus, some children with ASD may be less experienced with tackling written texts at school than TD students, who have numerous opportunities to practice reading in the classroom. This may lead to the known Matthew effect [78] with respect to literacy. The accepted notion posits that orthographic and morpho-orthographic learning is based on practicing graphemic-phonemic decoding [64]. Thus, limited experience may hamper the development of the morpho-orthographic identification strategy.

An alternative explanation for the slowness of reading that characterized the children with ASD states that many individuals with ASD are relatively slow processors. Slow processing in individuals with ASD was demonstrated in different cognitive tasks, including the Symbol Search subtest (WISC-III and -IV) and Rapid Visual-Motion Integration [79-82]. These tasks are commonly associated with learning and reading. 
An analysis of the correlation between accuracy and speed increases our understanding of the reading abilities of children with ASD. It is well established that in skillful reading, both accuracy and speed are high as well as highly correlated, indexing efficient reading [75]. Nevertheless, there may be a lower correlation between accuracy and speed in reading morphologically based pointed pseudowords. Accuracy in reading these words can be achieved by using the information derived from processing both the diacritics and the morphological patterns. On the one hand, paying attention to the diacritics increases accuracy; however, it is time-consuming. On the other hand, readers who ignore the diacritics can read fast but are liable to make mistakes. This speed-accuracy trade-off can effectively explain our findings of a lack of correlation between accuracy and speed in the three TD groups and of a weak correlation in the children with ASD.

In contrast to pointed pseudowords, the completion of the missing vowel information in reading unpointed pseudowords relies wholly on morpho-orthographic identification processes. Since this strategy encourages the reading of the unpointed pseudoword as one unit, it should speed up the reading [45]. Therefore, accuracy and speed are likely to be highly correlated in this type of reading. Unexpectedly, the second- and third-graders did not display a correlation between the two measures. The TD age-matched group, however, demonstrated a mild correlation. It is highly probable that the lack of correlation between accuracy and speed among the typical young readers indicates that they are in a phase wherein the knowledge is still unstable, and therefore accurate reading may come at the cost of slowing down, while fast reading may come at the cost of a decrease in accuracy (speed-accuracy trade-off). In contrast, the older readers, who probably already possess a skilled morpho-orthographic identification strategy, manifested more mature knowledge whereby readers were both accurate and fast.

Interestingly, a high correlation between accuracy and speed was found among the children with ASD, who, in this regard, were similar to their peers. A perusal of the distribution of the results for the children with ASD revealed a very wide range of achievements in both accuracy and speed in reading the unpointed pseudowords (Fig. 3). It appears that the children with ASD can be divided into two distinctive groups: a group of 9 children who were slow and inaccurate in reading the unpointed pseudowords, probably due to a delay in acquiring the morpho-orthographic identification strategy, and a sec- ond group of 11 children who showed similar achievements to those of their TD peers but were slightly slower.

We can thus conclude that based on reading abilities, the 31 children with ASD who were recruited for our original study can be divided into three almost equal groups: (1) a group of children with ASD who exhibited very poor reading abilities and were excluded from the final study, (2) a group of children who acquired the alphabetic knowledge but did not manage to progress to the morpho-orthographic phase, and (3) a group of children who possessed similar reading abilities to those of their typical peers. This outcome is again in line with the view of large variability in reading skills among the population of ASD.

\section{Conclusions}

The unique contribution of the current study is the enlargement of the scope by examining morpho-orthographic identification above and beyond graphemic-phonemic processing in ASD children's reading. By using this multidimensional observation, we were able to show that many (but not all) of the 12-year-old children with ASD were delayed by about 5 years in activating a morphoorthographic identification strategy for reading unpointed Hebrew pseudowords and were very slow readers even slower than TD second-graders. The results show that the reading abilities of children with ASD are not the typical ones; however, they do not show that they are unique to children with ASD. These findings have important implications for intervention programs targeting this population. It appears that it is very important to instruct these children explicitly in basic word recognition and fluency so as to facilitate the learning of the morphoorthographic system.

There are several reasons, however, to be careful not to overgeneralize the current findings. We recruited the ASD children according to a previous diagnosis that had been furnished by the education system in order to assign them to an appropriate educational setting. Moreover, the information related to the ASD children's reading, cognitive, and language abilities was provided only by their teachers. Additional detailed and formal test-based information related to real-word reading, as well as to the general and verbal IQ and particularly to phonological and morphological awareness, could better explain their limitations.

Thus, this study could be considered a pilot study, signifying that it is very likely that additional studies will 
be needed. We hope that the present study will provide preliminary evidence to help lay the foundation for future research in this domain. Future studies may also benefit from a comparison/control group of non-ASD students with reading/learning disabilities in order to ascertain whether it is the ASD that is delaying their reading, or whether the sample represents ASD students with the added burden of a serious reading/learning disability.

\section{Statement of Ethics}

We state that the subjects gave their informed consent and that the study protocol was approved by the institute's committee on human research and thus meets the standards of the Declaration of Helsinki in its revised version of 1975 and its amendments of 1983, 1989, and 1996.

\section{Disclosure Statement}

The authors have no conflict of interest to declare.

\section{References}

1 American Psychiatric Association: Autism spectrum disorder, 299.00 (F84.0). Diagnostic and Statistical Manual of Mental Disorders, ed 5. Arlington, American Psychiatric Publishing, 2013, pp 50-59.

2 National Research Council: Grand Challenges in Environmental Sciences. Washington, National Academies Press, 2001.

-3 Coolican J, Bryson SE, Zwaigenbaum L: Brief report: data on the Stanford-Binet Intelligence Scales (5th ed) in children with autism spectrum disorder. J Autism Dev Disord 2008;38:190-197.

4 Duncan AW, Bishop SL: Understanding the gap between cognitive abilities and daily living skills in adolescents with autism spectrum disorders with average intelligence. Autism 2015; 19:64-72.

5 Nation K, Clarke P, Wright B, Williams C: Patterns of reading ability in children with autism spectrum disorder. J Autism Dev Disord 2006;36:911-919.

6 Tager-Flusberg H: Defining language phenotypes in autism. Clin Neurosci Res 2006;6: 219-224.

7 Tomblin B: Co-morbidity of autism and SLI: kinds, kin and complexity. Int J Lang Commun Disord 2011;46:127-137.

8 Cronin KA: The relationship among oral language, decoding skills, and reading comprehension in children with autism. Exceptionality 2014;22:141-157.

-9 Grigorenko EL, Klin A, Volkmar F: Annotation: hyperlexia: disability or superability? J Child Psychol Psychiatry 2003;44:1079-1091.

10 Sparks R: Phonemic awareness and reading skill in hyperlexic children: a longitudinal study. Read Writ 2001;14:333-360.

11 Sparks R: Orthographic awareness, phonemic awareness, syntactic processing, and working memory skill in hyperlexic children. Read Writ 2004;17:359-386.

12 Åsberg J, Dahlgren Sandberg A: Dyslexic, delayed, precocious or just normal? Word reading skills of children with autism spectrum disorders. J Res Read 2012;35:20-31.
13 Cardoso-Martins C, Da Silva J-R: Cognitive and language correlates of hyperlexia: evidence from children with autism spectrum disorders. Read Writ 2010;23:129-145.

14 Huemer SV, Mann V: A comprehensive profile of decoding and comprehension in autism spectrum disorders. J Autism Dev Disord 2010;40:485-493.

15 Minshew NJ, Goldstein G, Taylor HG, Siegel DJ: Academic achievement in high functioning autistic individuals. J Clin Exp Neuropsychol 1994;16:261-270.

16 O'Connor IM, Klein PD: Exploration of strategies for facilitating the reading comprehension of high-functioning students with autism spectrum disorders. J Autism Dev Disord 2004;34:115-127.

17 Rumsey JM, Hamburger SD: Neuropsychological divergence of high-level autism and severe dyslexia. J Autism Dev Disord 1990;20: $155-168$.

18 Mayes SD, Calhoun SL: Analysis of WISC-III, Stanford-Binet:IV, and academic achievement test scores in children with autism. J Autism Dev Disord 2003;33:329-341.

19 Szatmari P, Tuff L, Finlayson MA, Bartolucci G: Asperger's syndrome and autism: neurocognitive aspects. J Am Acad Child Adolesc Psychiatry 1990;29:130-136.

20 Frith U, Snowling M: Reading for meaning and reading for sound in autistic and dyslexic children. Br J Dev Psychol 1983;1:329-342.

21 Jacobs DW, Richdale AL: Predicting literacy in children with a high-functioning autism spectrum disorder. Res Dev Disabil 2013;34: 2379-2390.

22 Newman TM, Macomber D, Naples AJ, Babitz T, Volkmar F, Grigorenko EL: Hyperlexia in children with autism spectrum disorders. J Autism Dev Disord 2007;37:760-774.

23 Ricketts J, Jones CR, Happé F, Charman T: Reading comprehension in autism spectrum disorders: the role of oral language and social functioning. J Autism Dev Disord 2013;43: 807-816.
24 Saldaña D, Carreiras M, Frith U: Orthographic and phonological pathways in hyperlexic readers with autism spectrum disorders. Dev Neuropsychol 2009;34:240-253.

25 Snowling M: Dyslexia. Oxford, Blackwell, 2000.

26 Smith Gabig C: Phonological awareness and word recognition in reading by children with autism. Commun Disord Q 2010;31:67-85.

27 Sparks RL: Phonemic awareness in hyperlexic children. Read Writ 1995;7:217-235.

28 Glosser G, Friedman RB, Roeltgen DP: Clues to the cognitive organization of reading and writing from developmental hyperlexia. Neuropsychology 1996;10:168-175.

29 Talero-Gutierrez C: Hyperlexia in Spanishspeaking children: report of 2 cases from $\mathrm{Co}-$ lombia, South America. J Neurol Sci 2006; 249:39-45.

- 30 Healy JM, Aram DM, Horwitz SJ, Kessler JW: A study of hyperlexia. Brain Lang 1982;17: $1-23$.

31 Nation K: Reading skills in hyperlexia: a developmental perspective. Psychol Bull 1999; 125:338-355.

- 32 Ziegler JC, Goswami U: Reading acquisition, developmental dyslexia, and skilled reading across languages: a psycholinguistic grain size theory. Psychol Bull 2005;131:3-29.

- 33 White S, Frith U, Milne E, Rosen S, Swettenham J, Ramus F: A double dissociation between sensorimotor impairments and reading disability: a comparison of autistic and dyslexic children. Cogn Neuropsychol 2006; 23:748-761.

- 34 Åsberg J, Kopp S, Berg-Kelly K, Gillberg C: Reading comprehension, word decoding and spelling in girls with autism spectrum disorders (ASD) or attention-deficit/hyperactivity disorder (AD/HD): performance and predictors. Int J Lang Commun Disord 2010;45:61-71.

35 Perfetti CA: The universal grammar of reading. Sci Stud Read 2003;7:3-24.

36 Share DL: On the Anglocentricities of current reading research and practice: the perils of overreliance on an "outlier" orthography. Psychol Bull 2008;134:584-615. 
37 Ehri LC: Phases of development in learning to read words by sight. J Res Read 1995;18:116125.

38 Perfetti CA: The representation problem in reading acquisition; in Gough PB, Ehri LC, Treiman R (eds): Reading Acquisition. Hillsdale, Lawrence Erlbaum, 1992, pp 145-174.

39 Seidenberg MS: Connectionist models of word reading. Curr Dir Psychol Sci 2005;14: 238-242.

40 Schreuder R, Baayen RH: Modeling morphological processing; in Feldman LB (ed): Morphological Aspects of Language Processing. Hillsdale, Lawrence Erlbaum, 1995, pp 131154.

41 Carlisle JF, Fleming J: Lexical processing of morphologically complex words in the elementary years. Sci Stud Read 2003;7:239-253.

-42 Burani C, Marcolini S, De Luca M, Zoccolotti P: Morpheme-based reading aloud: evidence from dyslexic and skilled Italian readers. Cognition 2008; 108:243-262.

43 Casalis S, Quémart P, Duncan LG: How language affects children's use of derivational morphology in visual word and pseudoword processing: evidence from a cross-language study. Front Psychol 2015;6:452.

44 Shalhoub-Awwad Y, Leikin M: The lexical status of the root in processing morphologically complex words in Arabic. Sci Stud Read 2016;20:296-310.

45 Bar-On A, Ravid D: Morphological decoding in Hebrew pseudowords: a developmental study. Appl Psycholinguist 2011;32:553-581.

46 Schiff R, Raveh M, Fighel A: The development of the Hebrew mental lexicon: when morphological representations become devoid of their meaning. Sci Stud Read 2012;16:383403.

47 Kirby JR, Deacon SH, Bowers PN, Izenberg L, Wade-Woolley L, Parrila R: Children's morphological awareness and reading ability. Read Writ 2012;25:389-410.

48 Schiff R, Lotem E: Effects of phonological and morphological awareness on children's word reading development from two socioeconomic backgrounds. First Lang 2010;31:139-163.

-49 Casalis S, Cole P, Sopo D: Morphological awareness in developmental dyslexia. Ann Dyslexia 2004;54:114-138.

50 Goodwin AP, Ahn S: A meta-analysis of morphological interventions in English: effects of literacy outcomes for school-age children. Sci Stud Read 2013;17:257-285.

51 Anderson SA: A-Morphous Morphology. Cambridge, Cambridge University Press, 1992.

52 McQueen JM, Cutler A: Morphology in word recognition; in Spencer A, Zwicky AM (eds): The Handbook of Morphology. Oxford, Blackwell, 1998, pp 406-427.
53 Seymour PH: Theoretical framework for beginning reading in different orthographies; in Joshi RM, Aaron PG (eds): Handbook of Orthography and Literacy. Mahwah, Lawrence Erlbaum, 2005, pp 441-463.

54 Frost R: Towards a universal model of reading. Behav Brain Sci 2012;35:263-279.

55 Ravid D: Spelling Morphology: The Psycholinguistics of Hebrew Spelling. New York, Springer, 2012.

56 Share DL, Bar-On A: Learning to read a Semitic Abjad: the triplex model of Hebrew reading development. J Learn Disabil 2017, Epub ahead of print

57 Share DL, Levin I: Learning to read and write in Hebrew; in Harris M, Hatano G (eds): Learning to Read and Write: A Cross-Linguistics Perspective. Cambridge, Cambridge University Press, 1999, pp 89-111.

58 Shany M, Bar-On A, Cohen-Katzir T: Learning to read the shallow deep dual Hebrew script: the long and winding road. Read Writ 2012;25:1217-1238.

59 Bar-On A, Datner E, Ravid D: Context effect on resolving heterophonic-homography in learning to read Hebrew. Read Writ 2017;30: 463-487.

60 Perfetti CA, Harris LN: Universal reading processes are modulated by language and writing system. Lang Learn Dev 2013;9:296316.

61 Seidenberg M: Reading in different writing systems: one architecture, multiple solutions; in McCardle P, Ren J, Tzeng O (eds): Dyslexia across Languages: Orthography and the Brain-Gene-Behavior Link. Baltimore, Paul Brooke Publishing, 2011.

62 Shany M, Lahman D, Shalem S, Bahat A, Zieger T: Alef ad taf: Manual. Tel Aviv, The MOFET Institute, 2006.

63 Bar-On A: The Role of Linguistic Knowledge in Learning to Read Non-Voweled Hebrew; doctoral dissertation, Tel Aviv University, 2010.

64 Share DL: Phonological recoding and selfteaching: sine qua non of reading acquisition. Cognition 1995;55:151-218; discussion 219226.

65 Rice ML, Rice ML, Warren SF: Growth models of developmental language disorders; in Rice ML, Warren SF (eds): Developmental Language Disorders: From Phenotypes to Etiologies. Psychology Press, 2004, pp 207-240.

66 Roberts JA, Rice ML, Tager-Flusberg H: Tense marking in children with autism. Appl Psycholinguist 2004;25:429-448.

67 Davidson MM, Ellis Weismer S: Characterization and prediction of early reading abilities in children on the autism spectrum. J Autism Dev Disord 2014;44:828-845.

68 Lucas R, Norbury CF: Levels of text comprehension in children with autism spectrum disorders (ASD): the influence of language phenotype. J Autism Dev Disord 2014;44: 2756-2768.
69 Klinger LG, Klinger MR, Pohlig RL: Implicit learning impairments in autism spectrum disorders: implications for treatment; in Perez JM, Gonzalez PM, Comi ML, Nieto C (eds): New Developments in Autism: The Future Is Today. London/Philadelphia, Jessica Kingsley Publishers, 2007, pp 76-103.

70 Courchesne E, Townsend J, Akshoomoff NA, Saitoh O, Yeung-Courchesne R, Lincoln AJ, James HE, Haas RH, Schreibman L, Lau L: Impairment in shifting attention in autistic and cerebellar patients. Behav Neurosci 1994; 108:848-865.

71 Kleinhans N, Akshoomoff N, Delis DC: Executive functions in autism and Asperger's disorder: flexibility, fluency, and inhibition. Dev Neuropsychol 2005;27:379-401.

72 Van Eylen L, Boets B, Steyaert J, Evers K, Wagemans J, Noens I: Cognitive flexibility in autism spectrum disorder: explaining the inconsistencies? Res Autism Spectr Disord 2011;5:1390-1401.

73 Seymour PH, Aro M, Erskine JM: Foundation literacy acquisition in European orthographies. Br J Psychol 2003;94(pt 2):143-174.

74 LaBerge D, Samuels SJ: Toward a theory of automatic information processing in reading. Cogn Psychol 1974;6:293-323.

75 Perfetti CA: Reading Ability. New York, Oxford University Press, 1985.

76 Samuels SJ: Reading fluency: its development and assessment; in Farstrup A, Samuels SJ (eds): What Research Has to Say about Reading Instruction, ed 3. Newark, International Reading Association, 2002, pp 166-184.

77 Zascavage VT, Keefe CH: Students with severe speech and physical impairments: opportunity barriers to literacy. Focus Autism Other Dev Disabl 2004;19:223-234.

78 Stanovich KE: Matthew effects in reading: some consequences of individual differences in the acquisition of literacy. Read Res Q 1986; 22:360-407.

79 Calhoun S-L, Mayes S-D: Processing speed in children with clinical disorders. Psychology in the Schools, 2005 vol 42, pp 333-343.

-80 Gepner B, Mestre D: Rapid visual-motion integration deficit in autism. Trends Cogn Sci 2002;6:455.

- 81 Hedvall Å, Fernell E, Holm A, Åsberg Johnels J, Gillberg C, Billstedt E: Autism, processing speed, and adaptive functioning in preschool children. ScientificWorldJournal 2013;2013: 158263.

82 Mayes SD, Calhoun SL: Learning, attention, writing, and processing speed in typical children and children with ADHD, autism, anxiety, depression, and oppositional-defiant disorder. Child Neuropsychol 2007;13:469-493. 